\title{
Survival and endocrine outome after testicular relapse in acute lymphoblastic leukaemia
}

\author{
R G Grundy, A D Leiper, R Stanhope, J M Chessells
}

\begin{abstract}
Survival and endocrine status in a cohort of boys with acute lymphoblastic leukaemia (ALL) who started treatment between 1972 and 1987 and subsequently developed a testicular relapse were analysed. During this period there was a significant improvement in the overall event free survival for boys, but no significant decrease in the testicular relapse rate. Thirty three boys had an apparently isolated testicular relapse, whereas 21 boys had a combined relapse. The event free survival for boys with an isolated testicular relapse was $59 \%$ at six years $(95 \%$ confidence interval (CI) 42 to $74 \%$ ). The event free survival for the 16 patients with a combined relapse who received a second course of treatment was $32 \%(95 \%$ CI 17 to $60 \%)$. Those patients receiving adequate second line treatment for an isolated testicular relapse whose first remission was longer than or equal to two years had an event free survival of $82 \%$ $(95 \%$ CI 63 to $93 \%)$ at six years. No boy relapsing within two years from diagnosis has survived. Endocrine late effects are significant, with $82 \%$ of the boys requiring hormonal treatment at some stage for induction of puberty or continuing pubertal maturation, or both. It is concluded that, despite the increasing intensity of initial treatment for ALL, isolated testicular relapse is treatable by conventional means in most patients. Careful endocrine follow up of these patients is essential as most will require hormone replacement treatment.

(Arch Dis Child 1997;76:190-196)
\end{abstract}

Keywords: acute lymphoblastic leukaemia; testicular relapse; late effects.

We and others have previously shown that the outlook for patients with an isolated testicular relapse of acute lymphoblastic leukaemia (ALL) is good and there is a significant chance of a prolonged second remission after conventional treatment. ${ }^{12}$ It is not clear, however, whether patients who relapse after more modern intensive treatment are equally curable or whether the outcome has changed since abandoning the routine taking of testicular biopsy samples before treatment is electively stopped. Retrieval treatment after testicular relapse, including testicular irradiation and systemic and central nervous system treatment, is effective, but has sequelae which become increasingly important with improved length of survival. We have therefore reviewed the outcome in all children with ALL treated at the Hospital for Sick Children between 1972 and 1987 whose first remission ended in an isolated testicular relapse, and have examined the endocrine status of all long term survivors.

Patients and methods

Seven hundred and sixty children with ALL were referred to the Hospital for Sick Children, Great Ormond Street between January 1972 and December 1987; 424 were boys. Patients have been followed up to July 1995.

INITIAL TREATMENT

The 15 year study was divided into three periods of progressively more intensive initial treatment: period 1, 1972-8, the early UK Acute Lymphoblastic Leukaemia (UKALL) trials $^{3}$; period 2, 1979-82, Great Ormond Street PLOD protocol and UK Children's Cancer Study Group (UKCCSG) protocol for T cell leukaemia ${ }^{45}$; and period 3, 1983-8, UKALL $\mathrm{X}$ pilot and UKALL $\mathrm{X}{ }^{6}$

Treatment in period 1 included three drug induction and continuing treatment with mercaptopurine, methotrexate, vincristine, and prednisolone. Patients in period 2 received more prolonged four drug induction and continuing treatment which included a randomisation to methotrexate given once a week by mouth or intramuscularly - the PLOD protocols. During this period patients with $\mathrm{T}$ cell disease were treated with the UKCCSG protocol. ${ }^{5}$ Period 3 included the pilot and full Medical Research Council UKALL X protocol with four drug induction, then randomisation to early consolidation or late consolidation, both versus no consolidation blocks followed by continuation treatment for up to two years. All patients received central nervous system directed treatment with cranial irradiation of 24 or 18 Gy and a course of intrathecal methotrexate. ${ }^{6}$ Before completing treatment all children had a bone marrow and lumbar puncture. Bilateral testicular wedge biopsy samples were taken, first retrospectively in mid-1977 and thereafter from all patients stopping treatment between 1977 and 1981, a negative biopsy sample being essential before stopping treatment. Routine biopsy samples were not taken after 1982 so that no child in period 3 had an end of treatment biopsy sample taken. All patients have been followed up to July 1995. 


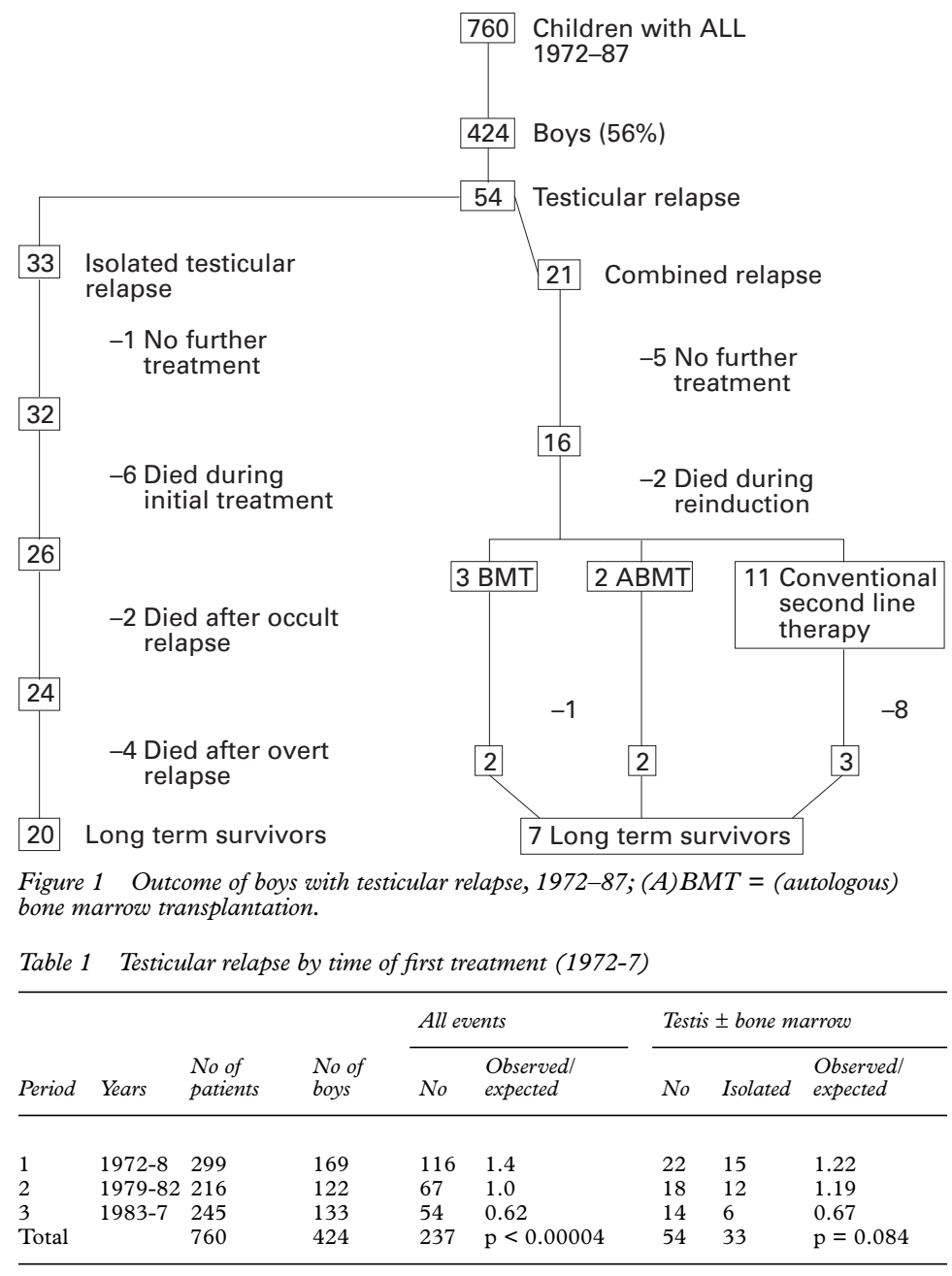

MANAGEMENT OF THE ISOLATED TESTICULAR RELAPSE

An isolated testicular relapse was proved by a wedge biopsy sample and concomitant bone marrow and cerebrospinal fluid examinations were performed. More exhaustive evaluation was not undertaken. ${ }^{7}$ Most patients received systemic reinduction and consolidation and continuation treatment with treatment directed towards the central nervous system with intrathecal methotrexate and local testicular irradiation. High dose intravenous methotrexate and epirubicin have been included in the management of relapse since 1987. Standard radiotherapy consisted of $24 \mathrm{~Gy}$ in 12 fractions to the testes and spermatic cords to the level of the internal iliac ring.

Two boys relapsing before 1977 received inadequate retrieval treatment with vincristine and prednisolone reinduction followed by radiotherapy and continuation therapy. Three boys received non-standard radiotherapy, two receiving only $12 \mathrm{~Gy}$, one of whom received only unilateral radiation. The third received 30 Gy due to a slow rate of testicular shrinkage while receiving radiotherapy. Allogeneic bone marrow transplantation was used in those boys relapsing during treatment if a histocompatible sibling donor was available. Pretransplantation preparation included cyclophosphamide and total body irradiation with a testicular boost.
MANAGEMENT OF A COMBINED RELAPSE

During this study period 21 additional patients sustained a combined relapse, with either central nervous system or bone marrow involvement, or both, and testicular disease. The treatment of choice for those with a histocompatible sibling donor was allogeneic bone marrow transplantation. Boys who did not have a suitable donor were considered for megatherapy with autologous bone marrow rescue. Otherwise second line treatment was broadly similar to that described earlier.

\section{ENDOCRINE ASSESSMENT}

Gonadal function was assessed clinically and biochemically. Pubertal status was defined using the criteria of Tanner, testicular volume was measured with a Prader orchidometer, ${ }^{89}$ and bone age was assessed by the Tanner and Whitehouse method in most patients. ${ }^{10}$ Entry into puberty was taken as the point at which genital development progressed from stage I to II. Testicular volume is reduced by testicular irradiation, thus testicular size cannot be used as an indicator of pubertal onset. Biochemical evidence of gonadal damage was sought by measuring basal serum gonadotrophins and testosterone in patients of pubertal age. Standard commercial reagents used in the endocrine laboratories of Great Ormond Street Hospital for Children NHS Trust and St Bartholomew's Hospital, London were used to determine hormone levels. Serum concentrations of luteinising hormone, follicle stimulating hormone, and testosterone were estimated by radioimmunoassay. All samples were taken during the daytime. Normal values for these laboratories for boys in early to mid-puberty are testosterone 11-33 nmol/1, basal luteinising hormone $0.5-1.8 \mathrm{IU} / 1$, and basal follicle stimulating hormone $0.5-2.0 \mathrm{IU} / 1$.

\section{STATISTICAL METHODS}

The results were analysed by log rank analysis using the SUREAL computer program.

\section{Results}

INCIDENCE OF A TESTICULAR RELAPSE

Four hundred and twenty four boys were treated between January 1972 and December 1987. Fifty four boys had a testicular relapse, 33 isolated and 21 in combination (fig 1). Of the combined group, two had a central nervous system and testicular relapse, 17 relapsed in the bone marrow and testes, and two relapsed in all three sites. Although the rate of testicular relapse has declined over the three periods of increasing intensity of initial treatment, the difference is not statistically significant (table 1). There was, however, a highly significant improvement in the overall event free survival $(\mathrm{p}<0.00004)$ (table 1$)$.

\section{TIMING OF ISOLATED TESTICULAR RELAPSE}

The time to relapse ranged from 22 to 1684 days with a median of 875 days. Six boys relapsed during treatment, ranging from 22 to 585 days after the start of treatment. Ten boys were found to have testicular leukaemia when a biopsy sample was taken at the end of 


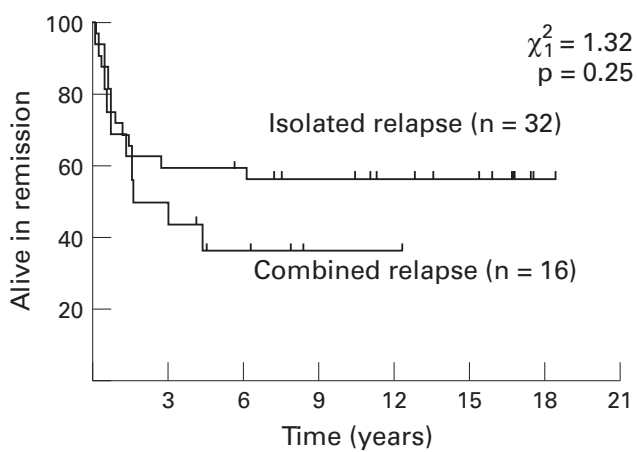

Figure 2 Comparative outcome for patients with isolated versus combined relapse.

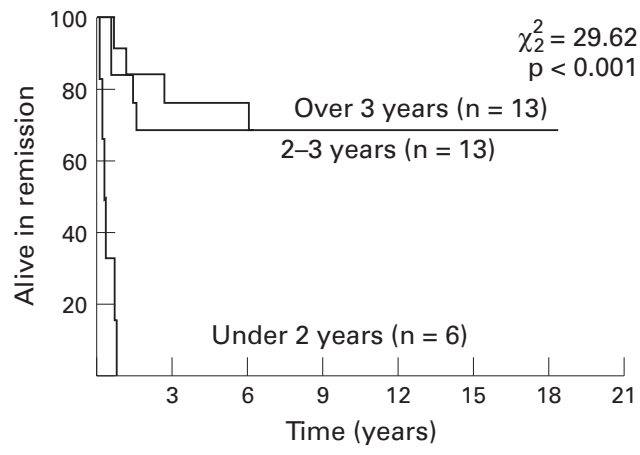

Figure 3 Survival by length of first remission.

treatment. Sixteen boys presented with overt testicular relapses after the end of treatment, nine of whom had negative end of treatment biopsy samples. Three boys were treated before the institution of routine taking of testicular biopsy samples and four after the end of this procedure.

Of the 16 children with an overt relapse after treatment, all but three relapsed in the first year after the end of treatment. The median time to relapse of an overt relapse was 150 days and the range 60-1684 days after the end of treatment. Overt relapse after a negative end of treatment biopsy sample occurred in nine boys: the median time to relapse was 35 weeks (range 8-156 weeks).

OUTCOME OF AN ISOLATED TESTICULAR RELAPSE As shown in fig 1, 32 patients with an isolated relapse and 16 patients with a combined relapse received further treatment and their outcome is shown in fig 2 , where the event free survival is $59 \%$ for isolated relapse and $32 \%$ for combined relapse at six years. In fig 3 the outcome for patients with an apparent isolated relapse is shown according to the length of the first remission.

There were no long term survivors who relapsed up to two years from diagnosis. Six boys presented with an overt relapse while receiving initial treatment. One died from septicaemia during reinduction, whereas five relapsed in the bone marrow after retreatment, one after allogeneic bone marrow transplantation. Occult testicular leukaemia was found in the end of treatment biopsy sample in 10 boys. Eight remain in long term remission from 126 to 200 months, whereas two have died, one fol- lowing a bone marrow relapse during retrieval treatment and the other after multiple relapses in the bone marrow and central nervous system. Sixteen boys had an overt relapse after treatment; four died subsequently despite further treatment. Three patients received inadequate treatment: the first presented with bilateral testicular disease 20 months after treatment and received retrieval chemotherapy plus a left orchidectomy and irradiation (12 Gy) of the right testis. He subsequently had a right sided testicular relapse and further treatment with bone marrow transplantation, but died. The second patient received only vincristine and prednisolone reinduction therapy followed by irradiation and maintenance. He had two further bone marrow relapses before dying and it is possible that more intensive treatment may have been successful in this case. The third received vincristine and prednisolone reinduction and 15 Gy testicular irradiation; he subsequently had a central nervous system and bone marrow relapse, but is now in long term remission. One boy received 30 Gy testicular irradiation due to a slow local response to radiotherapy. $\mathrm{He}$ later suffered a central nervous system relapse and died from toxicity during bone marrow transplantation.

Excluding the patients who received inadequate treatment, the event free survival for the patients who relapsed after more than two years is $82 \%$ (95\% confidence interval (CI) 49 to $82 \%$ ).

Overall, 20 patients are off treatment in second remission, ranging from 48 to 200 months (median 120 months) (fig 3). There was no significant difference in second remission outcome between those presenting either with an occult or an overt relapse, suggesting that there is no benefit in taking an end of treatment testicular biopsy sample (table 2).

FACTORS INFLUENCING THE LENGTH OF SECOND REMISSION AFTER AN ISOLATED RELAPSE

Factors influencing remission were analysed by $\log$ rank analysis. There was no significant difference in white cell count, age at presentation, nor the time period during which they received treatment between those remaining in second remission and those in whom second line treatment was unsuccessful (table 2). The most important prognostic factor for prolonged second remission was the length of the first remission $(\mathrm{p}>0.02)($ table 2$)$.

\section{OUTCOME OF COMBINED TESTICULAR RELAPSE}

Twenty one boys had a combined relapse; five patients were not treated, leaving 16 patients. Five of these underwent bone marrow transplantation, three allogeneic and two autologous (fig 1). The second treatment for the remaining 11 patients was broadly similar to that for isolated testicular relapse. The overall event free survival for boys with a combined relapse was $32 \%$ (95\% CI 17 to $60 \%)$. There are seven survivors, three of whom received conventional treatment. The outcome of boys with an isolated relapse is compared with those with a combined relapse in fig 2. Although the 
Table 2 Factors influencing secondary remission after isolated testicular relapse

\begin{tabular}{|c|c|c|c|c|c|}
\hline Factor & No & Observed & Expected & Observed/expected & $p$ Value \\
\hline \multicolumn{6}{|l|}{ Age at diagnosis (years) } \\
\hline$<3$ & 4 & 1 & 2.11 & 0.47 & \multirow{3}{*}{0.204} \\
\hline 3-7 & 17 & 7 & 7.83 & 0.89 & \\
\hline$>7$ & 11 & 6 & 4.04 & 1.48 & \\
\hline \multicolumn{6}{|l|}{ Year of first treatment } \\
\hline $1972-8$ & 15 & 5 & 6.82 & 0.73 & \multirow{3}{*}{0.408} \\
\hline $1979-82$ & 11 & 6 & 4.74 & 1.28 & \\
\hline 1983-7 & 6 & 3 & 2.47 & 1.26 & \\
\hline \multicolumn{6}{|l|}{ Type of relapse } \\
\hline Overt & 21 & 11 & 9.09 & 1.21 & \multirow[b]{2}{*}{0.284} \\
\hline Occult & 11 & 3 & 4.91 & 0.61 & \\
\hline \multicolumn{6}{|c|}{ Length of first remission (days) } \\
\hline-730 & 6 & 6 & 0.93 & 6.45 & \multirow{3}{*}{0.002} \\
\hline-1094 & 13 & 4 & 6.53 & 0.61 & \\
\hline-1460 & 11 & 4 & 5.41 & 0.74 & \\
\hline-3650 & 2 & 0 & 1.13 & 0.00 & \\
\hline \multicolumn{6}{|c|}{ Initial white cell count $\left(\times 10^{9} / 1\right)$} \\
\hline$<50$ & 27 & 12 & 12.64 & 0.95 & \multirow{3}{*}{0.579} \\
\hline $50-100$ & 2 & 1 & 0.79 & 1.45 & \\
\hline$>100$ & 3 & 1 & 0.67 & 1.50 & \\
\hline \multicolumn{6}{|l|}{ Type of treatment } \\
\hline Non-standard & 3 & 3 & & 3.13 & \\
\hline Standard & 16 & 4 & & 0.53 & \\
\hline Intensified & 12 & 6 & & 1.14 & \\
\hline Bone marrow transplant & 1 & 1 & & 3.54 & 0.09 \\
\hline
\end{tabular}

numbers are relatively small, the fate of those with a combined relapse is clearly worse.

\section{ENDOCRINE STATUS}

The endocrinological outcome of long term survivors of testicular relapse is summarised in table 3 . Of the seven survivors with a combined relapse, four underwent bone marrow transplantation. Because of the extensive endocrine late effects that follow such treatment these patients are not considered further, leaving three evaluable boys. All but one of the 20 long term survivors of an isolated relapse is of pubertal age. Thus the three long term survivors of combined relapse who received conventional treatment and the 19 survivors of an isolated relapse, now of pubertal age, make a total of 22 evaluable boys. Puberty was induced in 16 of these boys, with six entering puberty spontaneously, although two subsequently required sex hormone replacement therapy for pubertal arrest. Overall 18 boys
$(82 \%)$ are now receiving sex hormone replacement therapy.

The mean (SD) age at testicular radiation in the group entering puberty spontaneously was 9.54 (1.8) years compared with 7.68 (3) years in those requiring pubertal induction. Nineteen of the 22 pubertal patients had raised follicle stimulating hormone levels and 18 of 22 had raised luteinising hormone levels, suggesting gonadal damage. Two patients had normal plasma levels of follicle stimulating hormone and luteinising hormone, but did not enter puberty at 13 and 13.8 years, suggesting a diagnosis of hypogonadotropic hypogonadism. Six boys had compensated hypogonadism, but entered puberty spontaneously despite increased gonadotropins. Two boys of this group now require testosterone replacement due to arrested pubertal maturation. The age at entry into puberty is compared with the normal population in fig 4. All except three entered puberty later than average, six boys more than $1 \mathrm{SD}$ from the mean and seven more than $2 \mathrm{SD}$ from the mean. Most of those entering puberty spontaneously did so late, four of the six greater than 1 SD from the mean. Because of the age group studied, no formal assessment of semen was made in this series of patients, except for two subjects who were azoospermic.

\section{Discussion}

Gender remains an important prognostic factor in the treatment of ALL, with boys, in most trials, having a worse outcome. ${ }^{11-13}$ This may be due either to the testis acting as a sanctuary site or to inadequate systemic treatment. The blood-brain barrier forms an anatomical basis for considering the central nervous system as a sanctuary site; there is, however, no clear evidence for such a barrier in the testis. Histological examination of testicular leukaemia shows that most blasts are found in the interstitium, with little evidence for tubular infiltration. ${ }^{14}$ Methotrexate and cyclophosphamide can penetrate this interstitial space, albeit

Table 3 Endocrine outcome after treatment of testicular relapse

\begin{tabular}{|c|c|c|c|c|c|c|}
\hline \multirow[b]{2}{*}{ Patient No } & \multirow{2}{*}{$\begin{array}{l}\text { Age at } \\
\text { puberty } \\
\text { (years) }\end{array}$} & \multirow[b]{2}{*}{$\begin{array}{l}\text { Puberty } \\
\text { induced }\end{array}$} & \multirow[b]{2}{*}{$\begin{array}{l}\text { Currently receiving sex } \\
\text { hormone therapy }\end{array}$} & \multicolumn{3}{|c|}{ Hormone profile at induction or currently } \\
\hline & & & & $\begin{array}{l}\text { Testosterone } \\
\text { (nmol/l) }\end{array}$ & $L H(I U / l)^{*}$ & FSH $(I U / l) \dagger$ \\
\hline 1 & 14.0 & No & No & 16.7 & 16.2 & 40.0 \\
\hline 2 & 11.7 & No & No & 8.5 & 24.2 & 30.1 \\
\hline 3 & 13.0 & No & No & 13.0 & 41.8 & $>50.0$ \\
\hline 4 & 12.8 & No & No & 15.8 & 14.8 & 63.6 \\
\hline 5 & 13.4 & No & Yes & 3.5 & 25.0 & 40.5 \\
\hline 6 & 13.7 & No & Yes & 6.0 & 38.5 & 29.3 \\
\hline 7 & 13.1 & Yes & Yes & 0.5 & 21.6 & 32.6 \\
\hline 8 & 14.0 & Yes & Yes & 1.6 & 10.2 & 34.9 \\
\hline 9 & 14.6 & Yes & Yes & 0.9 & 12.0 & 34.2 \\
\hline 10 & 14.0 & Yes & Yes & 0.6 & 2.2 & 9.3 \\
\hline 11 & 12.3 & Yes & Yes & 1.4 & 10.3 & 16.3 \\
\hline 12 & 12.4 & Yes & Yes & 0.7 & 21.0 & 16.0 \\
\hline 13 & 13.0 & Yes & Yes & 0.7 & 1.4 & 1.5 \\
\hline 14 & 13.3 & Yes & Yes & 0.4 & 1.2 & 12.0 \\
\hline 15 & 15.3 & Yes & Yes & 0.7 & 3.4 & 18.3 \\
\hline 16 & 13.2 & Yes & Yes & 2.0 & 2.4 & 7.2 \\
\hline 17 & 13.8 & Yes & Yes & 0.8 & 1.5 & 1.0 \\
\hline 18 & 14.3 & Yes & Yes & 3.1 & 20.1 & 13.3 \\
\hline 19 & 13.1 & Yes & Yes & 0.8 & 9.8 & 38.2 \\
\hline 20 & 12.3 & Yes & Yes & 0.8 & $<0.8$ & 1.5 \\
\hline 21 & 14.3 & Yes & Yes & - & 25.4 & 58.8 \\
\hline 22 & 14.5 & Yes & Yes & 9.8 & 9.8 & 38.2 \\
\hline
\end{tabular}

*Luteinising hormone.

†Follicle stimulating hormone. 


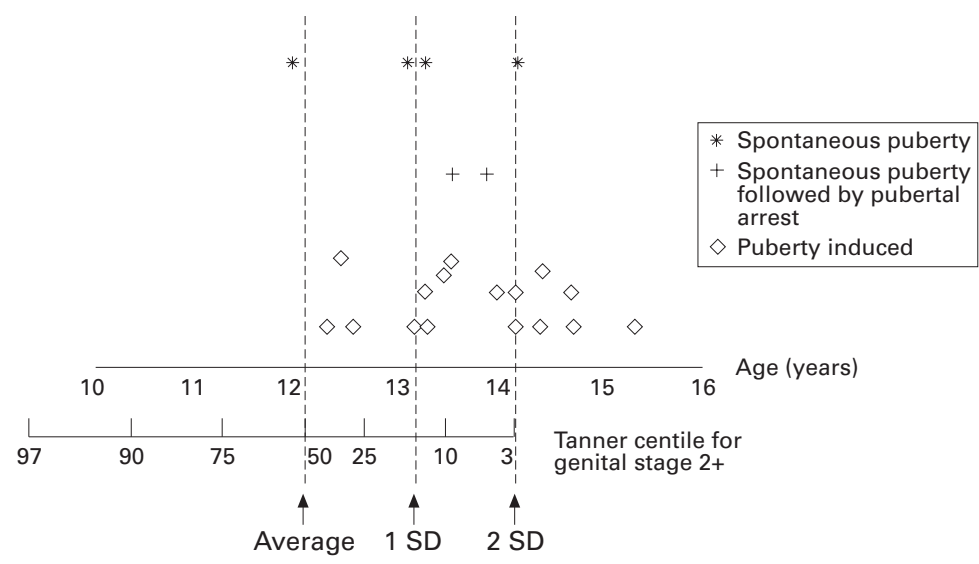

Figure 4 Age of entry into puberty of survivors of testicular relapse.

at reduced concentration compared with plasma levels, suggesting that this pharmacological 'sanctuary' can be overcome by appropriate drug scheduling. ${ }^{15}{ }^{16}$ Indeed, the rate of testicular relapse is lowest in those trials of childhood lymphoblastic leukaemia incorporating moderate intravenous and high dose methotrexate. ${ }^{17-20}$ Furthermore, although prophylactic testicular irradiation eradicates testicular leukaemia, it does not improve the overall prognosis for boys and has unacceptable late effects. ${ }^{21} 22$ This suggests that testicular relapse reflects the failure of conventional treatment to eradicate minimal residual disease and that it would be obviated by more intensive treatment.

In the three consecutive periods of increasing treatment intensity there was a highly significant improvement in the overall rate of event free survival. Although the incidence of isolated testicular relapse has decreased over the same time periods, the difference was not significant and did not reflect the overall improved outcome. The isolated testicular relapse rate of $7.8 \%$ in this series lies within the reported range and is similar to our previously reported figure. ${ }^{1223-28}$ There was no significant change in the event free survival for an isolated testicular relapse over the three periods of increasing intensity of initial treatment. Thus intensive first line treatment has not adversely affected the chances of a prolonged second remission. The event free survival of $59 \%$ in our group reflects the poor outcome of those relapsing during treatment, all of whom died. The outcome for those boys who remained in first remission until the end of the initial treatment and received adequate second line treatment is considerably better, with an event free survival of $82 \%$ at six years. This level of success is perhaps surprisingly high as we now know from molecular studies that a true isolated extramedullary relapse is rare. ${ }^{29}$ Submicroscopic bone marrow disease can be detected by molecular analysis in most patients with a clinically determined isolated relapse. ${ }^{29}$ This reinforces the need for systemic and central nervous system directed therapy in second line treatment. Furthermore, although most patients did not receive novel drugs or intensive treatment by modern standards, the outcome is favourable. This is consistent with boys receiving inadequate initial treatment, most likely due to decreased sensitivity to continuation therapy. ${ }^{11}$

The rate of combined relapse has not changed significantly in the most recent time period, suggesting that the end of taking routine biopsy samples has not resulted in increased presentation with disseminated disease and that the reduction in the rate of isolated testicular relapse is not due to relapse elsewhere. In our series a negative end of treatment biopsy sample was a poor predictor of future events. Overt relapse after a negative end of treatment biopsy sample occurred in nine boys, two of these presenting eight weeks after a normal biopsy sample had been taken. A routine testicular biopsy sample therefore did not detect residual blast cells in these patients. There was no difference in outcome between those presenting with overt versus occult disease in our series. This suggests that cessation of end of treatment biopsies has not had an adverse effect on disease free survival. A larger study of 708 boys who had an end of treatment biopsy sample taken also concluded that this practice did not significantly improve disease free survival for boys with ALL. ${ }^{30}$ As we have shown here, overt testicular relapse after treatment is curable in $82 \%$ of patients, therefore, there is little advantage in attempting to detect testicular relapse in the occult phase. As taking a testicular biopsy sample is not without potential risks, ${ }^{30}{ }^{31}$ this practice can no longer be supported. It is possible that more intensive primary treatment may delay the time to relapse, but in this study there is no statistical difference in the mean time to relapse during the differing treatment periods. Again, longer follow up will be required to exclude this possibility. The only significant factor influencing the prognosis for second remission was the timing of the relapse. All of those relapsing during treatment died, presumably due to drug resistant disease.

The endocrinological consequences of effective treatment in this group are considerable, $82 \%$ of those of pubertal age and older now requiring regular testosterone replacement. Six boys entered puberty spontaneously, but two of these subsequently required testosterone replacement due to pubertal arrest. Thus even those children entering puberty spontaneously need careful long term endocrine follow up. All four boys who have not required androgen replacement show compensated hypogonadism with markedly increased gonadotrophins. $\mathrm{Pu}-$ berty was induced with sex steroid replacement therapy in 16 boys who did not enter puberty spontaneously. Notwithstanding the difficulties of interpretation of basal luteinising hormone and follicle stimulating hormone levels in patients who have received testicular and cranial irradiation, most of this group had increased gonadotrophins or hypogonadotrophic hypogonadism. We and others have previously shown that 24 Gy causes Leydig cell failure; this study thus confirms the prediction that most patients will require long term androgen replacement. ${ }^{32-35}$ The risk of perma- 
nent Leydig cell damage appears to be related to age at irradiation, being greater if radiation is given during early childhood. ${ }^{32}$ In our group those patients entering puberty spontaneously were older at irradiation than the group that did not enter puberty without sex hormone treatment. As the recovery of Leydig cell function is unlikely after irradiation, especially if such treatment is given in the prepubertal era, ${ }^{32}{ }^{33}$ there is probably little to be gained by delaying the initiation of puberty. In view of the psychological pressures brought to bear on a child by the diagnosis of malignant disease, we feel that it is unwise to compound these effects to allow pubertal delay with resultant peer group pressure. Hence our current policy is to induce puberty at an age not greater than $1 \mathrm{SD}$ from the mean.

The one surviving patient who received 12 Gy of testicular irradiation has not required hormonal replacement therapy. He spontaneously entered puberty at 14 years (2 SD), despite markedly increased basal gonadotropin levels. A similar pattern has been seen in other boys who received between 12 and 15 Gy of testicular irradiation. ${ }^{22}$ Although these boys are likely to be sterile, Leydig cell function is often sufficiently preserved at this lower dose to enable pubertal development. Thus using 12 or $15 \mathrm{~Gy}$, instead of $24 \mathrm{~Gy}$, of testicular irradiation in the management of testicular relapse of ALL is attractive in terms of the long term consequences. The efficacy of this lower dose is not proved, certainly doses lower than 12 Gy are suboptimum, ${ }^{36}$ and, although some groups have suggested that 12 Gy should be used in the treatment of testicular relapse, ${ }^{28}$ it is not clear that this dose provides adequate treatment. Based on the radiosensitivity of testicular leukaemia to radiotherapy, ${ }^{37}$ most workers suggest that doses above 22 Gy should be used. ${ }^{123} 242738-40$ Occasionally higher doses are required if there is a poor local response, as in one of our patients. ${ }^{41}$ As testicular relapse is a marker for persistent leukaemia warranting aggressive treatment, we feel that 24 Gy is still indicated as part of the treatment of testicular relapse despite the long term sequelae. The low incidence of testicular relapse reported in studies using intravenous methotrexate $e^{17-20}$ are exciting and may herald a reduction in this complication. Analysis of the outcome of boys receiving this treatment will be of interest.

The adequacy of the testosterone dose was assessed by direct questioning of sexual function: the number of early morning erections, emissions per week, and libido. Although sexual function was not formally assessed, the young adults receiving testosterone appeared to be satisfied with their level of sexual function. It may be of interest to investigate this more formally by a questionnaire study. Similar findings with respect to secondary sexual characteristics and adequacy of sexual function have been reported in a group of boys with ALL and radiation induced Leydig cell failure. This study also found that seven of eight boys achieved their target genetic height. ${ }^{42}$

Leukaemic infiltration of the testes has been postulated as one of the mechanisms leading to

\section{Key messages}

- Testicular relapse remains an important cause of the failure to cure boys with ALL

- Isolated testicular relapse after treatment carries an $82 \%$ six year survival with adequate retrieval treatment

- Patients developing a testicular relapse during treatment fare badly

- Endocrine sequelae in this group of patients are significant, but treatable; long term follow up is essential

Leydig cell dysfunction after testicular relapse. ${ }^{35}$ In this series four of the six children who entered puberty spontaneously had bilateral testicular infiltration at relapse, providing indirect evidence that interstitial involvement by blast cells per se is not the major factor. The evaluation of cause and effect leading to Leydig cell failure in these patients is complex due to the diversity of the treatments received. One study has looked at the endocrine sequelae in a group of boys who received identical chemotherapy, but differing radiotherapy-either cranial, craniospinal, or cranial plus testicular radiotherapy for localised relapse. Leydig cell function was not affected by chemotherapy, but only by testicular radiotherapy in doses higher than $12 \mathrm{~Gy} .^{43}$ Other studies have found similar results, ${ }^{44}{ }^{45}$ one group, however, finding that their patients had evidence of compensated hypogonadism reflecting gonadal damage on laboratory testing. ${ }^{46}$ As chemotherapy and leukaemic infiltration are not implicated, testicular irradiation using a dose of 24 Gy must be the major factor leading to Leydig cell failure, although occasionally hypogonadotrophic hypogonadism is observed, presumably due to concurrent cranial radiotherapy.

Although all the boys in this study receiving $24 \mathrm{~Gy}$ of testicular irradiation had reduced testicular volume, only one patient requested testicular implants. Obtaining samples for analysis of sperm count has been difficult, but of the two performed, both were azoospermic, as predicted. $^{22}$

We conclude that isolated testicular relapse after the completion of treatment carries a relatively good prognosis with retrieval therapy that includes systemic reinduction, 24 Gy testicular irradiation, central nervous system directed, and continuation therapy. Increasingly intensive first line treatment does not appear to have adversely affected the chances of a prolonged second remission. Preliminary evidence suggests that the incidence of an isolated testicular relapse may be declining with more intensive chemotherapy, although the possibility that the time to relapse is prolonged cannot yet be excluded. As there has been no absolute increase in the number of isolated testicular or combined relapses since the end of taking a routine biopsy sample, this practice is no longer of benefit. The long term consequences of retrieval treatment include sterility and endocrine dysfunction, with most patients 
requiring sex steroid supplementation to progress through puberty, and to retain secondary sexual characteristics, libido, and sexual function.

Supported by grants from the Leukaemia Research Fund (J M Chessells), the Medical Research Council (R G Grundy and A Grundy). We thank Lisa Luxon for her enduring and excellent secretarial support and Ian Hann for his helpful comments.

1 Tiedemann K, Chessells JM, Sandland RM. Isolated testicular relapse in boys with acute lymphoblastic leukaemia: treatment and outcome. BMF 1982;285:1614-6.

2 Bowman WP, Aur RJA, Hustu O, Rivera G. Isolated testicular relapse in acute lymphocytic leukemia of childhood: categories and influence on survival. $\mathcal{f}$ Clin Oncol 1984;2:924-9.

3 Medical Research Council. Improvement in treatment for children with acute lymphoblastic leukaemia. Lancet 1986 i: $408-11$.

4 Chessells JM, Leiper AD, Tiedemann K, Hardisty RM, Richards S. Oral methotrexate is as effective as intramuscular in continuing (maintenance) therapy of acute lymphoblastic leukaemia. Arch Dis Child 1987;62:172-6.

5 Mott MG, Chessells JM, Willoughby MLN, et al. Adjuvant low dose radiation in childhood $\mathrm{T}$ cell leukaemia/ low dose radiation in childhood $T$

6 Chessells JM, Bailey C, Richards SM. Intensification of treatment and survival in all children with lymphoblastic leukaemia: results of UK Medical Research Council trial leukaemia: results of UK Medical
UKALL X. Lancet 1995;345:143-8.

7 Baum E, Heyn R, Nesbit M, Tilford D, Nachman J. Occult abdominal involvement with apparently isolated testicula relapse in children with acute lymphocytic leukemia. $A m \mathcal{F}$ Pediatr Hematol Oncol 1984;6:343-6.

8 Tanner JM. Growth at adolescence. 2nd Ed. Oxford: Blackwell Scientific, 1973.

9 Prader A. Testicular size: assessment and clinical importance. Triangle 1966;7:240-3.

10 Greulich WW, Pyle SI. Radiologic atlas of skeletal development of the hand and wrist. 2nd Ed. California: Stanford University Press, 1959.

11 Chessells JM, Richards SM, Bailey CC, Lilleyman JS, Eden OB. Gender and treatment outcome in childhood lymphoblastic leukaemia: report from

12 Sather H, Miller D, Nesbit M, Heyn R, Hammond DG. Differences in prognosis for boys and girls with acute lymphoblastic leukaemia. Lancet 1981;i:741-3.

13 Lanning $M$, Garwicz S, Hertz $\mathrm{H}$, et al. Superior treatmen results in females with high-risk acute lymphoblastic leukemia in childhood. Acta Paediatr Scand 1992;81:66-8.

14 Kay HEM. Testicular infiltration in acute lymphoblastic leukaemia. Br f Haematol 1993;53:537-42.

15 Riccardi R, Vigersly RA, Barnes S, Bleyer WA, Poplack DG Methotrexate levels in the interstitial space and reminiferous tubule of the rat testis. Cancer Res 1982;42:1617-9.

16 Forest JB, Turner TT, Howards SS. Cyclophosphamide and blood testis barrier. Surg Forum 1979;30:552-3.

17 Moe PJ, Seip M, Finne PH. Intermediate dose of methotrexate (IDM) in childhood acute lymphocytic leukemia in Norway. Acta Paediatr Scand 1981;70:73-9.

18 Brecher ML, Weinberg V, Boyett JM, et al. Intermediate dose methotrexate in childhood acute lymphoblastic leukemia resulting in decreased incidence of testicular relapse. Lancet 1986;58:1024-8.

19 Freeman AI, Weinberg V, Brecher ML, et al. Comparison of intermediate-dose methotrexate with cranial irradiation for the post-induction treatment of acute lymphocy
mia in children. $N$ Engl f Med 1983;308:477-84.

20 Reiter A, Schrappe Engl f Med 1983;308:477-84. 998 unselected childhood acute lymphoblastic leukemia patients, results and conclusions of the multicenter trial ALL-BFM 86. Blood 1994;84:3122-33.

21 Eden OB, Lilleyman JS, Richards S. Testicular irradiation in childhood lymphoblastic leukaemia. Br f Haematol 1990; 75:496-8.

22 Castillo LA, Craft AW, Kernhan J, Evans RGB, AynsleyGreen A. Gonadal function after 12-Gy testicular irradiation in childhood acute lymphoblastic leukaemia. Med Pediatr Oncol 1990;18:185-9.
23 Eden OB, Rankin A, Kay HEM. Isolated testicular relapse in the treatment of childhood acute lymphoblastic leukaemia. Arch Dis Child 1983;58:128-32.

24 Oakhill A, Mainwaring D, Hill FGH, et al. Management of leukemic infiltration of the testis. Arch Dis Child 1980;55: 564-6.

25 Askin FB, Land VJ, Sullivan MP, et al. Occult testicular leukaemia: testicular biopsy at three years continuous complete remission of childhood leukemia. Cancer 1981;47: plete r.

26 Nesbit ME, Robinson K, Ortega JA, Sather HN, Donaldson $M$, Hammond D. Testicular relapse in childhood acute lymphoblastic leukaemia: association with pre-treatment patient characteristics and treatment. Cancer 1980;45: 2009-16.

27 Byrd R. Testicular leukaemia: incidence and management results. Med Pediatr Oncol 1981;9:493-500.

28 Stoffel TJ, Nesbit ME, Levitt SH. Extramedullary involvement of the testes in childhood leukaemia. Cancer 1975;35: 1203-11.

29 Goulden N, Langlands K, Steward C, et al. PCR assessment of bone marrow status in 'isolated' extramedullary relapse of childhood B-precursor acute lymphoblastic leukaemia. Brf Haematol 1994;87:282-5.

30 Nachman J, Palmer NF, Sather HN, et al. Open-wedge testicular biopsy in childhood acute lymphoblastic leukemia after two years of maintenance therapy: diagnostic accuracy and influence on outcome-a report from Children's Canand influence on outcome-a report fro

31 Chan KW, Wood BJ, Johnson HW. Testicular adhesion; a potential complication from testicular biopsy in childhood eukaemia. Med Pediatr Oncol 1988;16:366-7.

32 Leiper AD, Grant DB, Chessells JM. Gonadal function after testicular irradiation for acute lymphoblastic leukaemia. Arch Dis Child 1986;61:53-6.

33 Shalet SM, Horner A, Ahmed SR, Morris-Jones PH. Leydig cell damage after testicular irradiation for lymphoblastic leukaemia. Med Pediatr Oncol 1985;13:65-8.

34 Brauner R, Czernichow P, Cramer P, Schaison G, Rappaport R. Leydig cell function after direct testicular irradiation for acute lymphoblastic leukaemia. $N$ Engl $\mathcal{F}$ Med 1983;309:25-8.

35 Blatt J, Sherrins RJ, Niebrugge D, Bleyer WA, Poplack DG. Leydig cell function in boys following treatment for testicular relapse of acute lymphoblastic leukaemia. 7 Clin Oncol 1985;3:1227-31.

36 Steinfield AD. Radiation therapy in the treatment of leukemic infiltrate of the testes. Radiology 1976;120:681-2.

37 Atkinson K, Thomas PRM, Peckham MJ, McElwain TJ. Radiosensitivity of the acute leukemic infiltrate. Eur 7 Cancer 1976;12:534-5.

38 Tombolini V, Banelli E, Capua A, Giona F, Vitturini A. Radiation treatment of testicular relapse in acute lymphoblastic leukemia. Acta Radiol Oncol 1986;25:29-32

39 Smith SD, Trueworthy RC, Klopvitch PM, Vats TS, Snodgrass W. Management of children with isolated testicular leukaemia. Cancer 1984;54:2848-54.

40 Sullivan MP, Perez CA, Herson J, et al. Radiotherapy (2500 rad) for testicular leukemia. Cancer 1992;46:508-15.

41 Mirro J, Wharam MD, Kaizer H, Zinkham W, Leventhal BG. Testicular leukaemic relapse: rate of regression and persistent disease after radiation therapy. 7 Pediatr 1981;99: 493-40.

42 Didi M, Morris-Jones PH, Gattamaneni HR, Shalet SM. Pubertal growth in response to testosterone replacement therapy for radiation-induced leydig cell failure. Med Pediatr Oncol 1994;22:250-4.

43 Sklar CA, Robison LL, Nesbit ME, et al. Effects of radiation on testicular function in long-term survivors of childhood acute lymphoblastic leukemia: a report from the Children's Cancer Study Group. 7 Clin Oncol 1990;8:1981-7.

44 Blatt J, Poplack DG, Sherrins RJ. Testicular function in boys after chemotherapy for acute lymphoblastic leukaemia. $N$ Engl F Med 1981;304:1121-4.

45 Shalet SM, Hann IM, Lendon M, Morris-Jones PH, Beardwell CG. Testicular function after combination chemotherapy in childhood in childhood for acute lymphoblastic leukaemia. Arch Dis Child 1981;56:275-8.

46 Quigley C, Cowell C, Jimenez M, et al. Normal or early development of puberty despite gonadal damage in children treated for acute lymphoblastic leukemia. $N \mathrm{Engl} F$ Med 1989;321:143-51. 